\title{
THE OSSIFICATION AND VASCULARISATION OF THE TARSAL NAVICULAR AND THEIR RELATION TO KÖHLER'S DISEASE
}

\author{
W. WAUgh, NotTingham, England
}

From the Nuffield Orthopaedic Centre, Oxford

Study of the nature of the abnormal radiographic appearances in the tarsal navicular bone first described by Köhler (1908) presents difficulties which arise in any mild and selflimiting condition. Pathological specimens are seldom available and can demonstrate only a static phase in a continually changing process occurring in a growing bone. Köhler's (1928) final writing on the subject represents a careful assessment of the situation, particularly so far

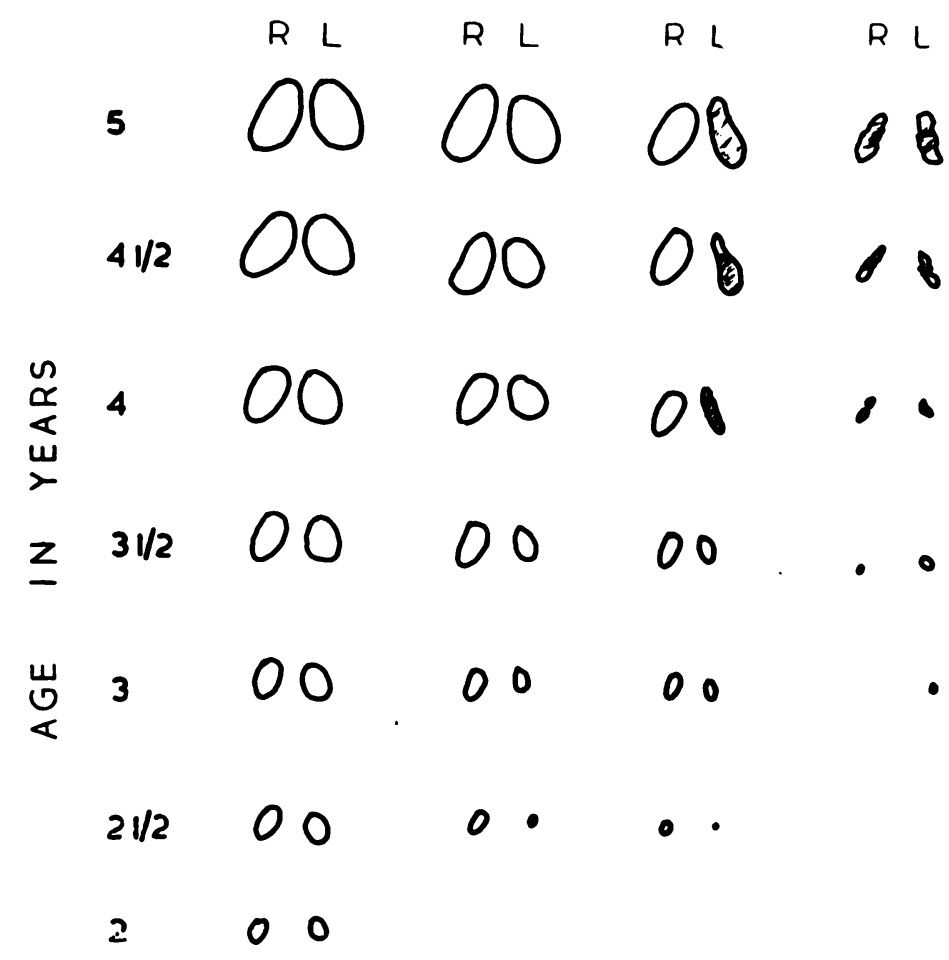

Fig. 1

Tracings of the outlines of the navicular from lateral radiographs of both feet in four children. Radiographs were taken every six months between two and five years. These examples demonstrate normal and abnormal ossification.

as etiology is concerned, and very little knowledge has been added since. The problem has to be approached indirectly, and the object of this paper is to report an investigation into normal and abnormal patterns of ossification and vascularisation of the growing tarsal navicular and their relation to Köhler's disease. Three groups of material have been collected and analysed: first, serial radiographs of fifty-two normal children's feet; second, post-mortem injection studies using the technique developed at the Nuffield Orthopaedic Centre (Trueta and Harrison 1953); and third, the records of sixty-two children with Köhler's disease. 
NORMAL AND ABNORMAL OSSIFICATION OF THE NAVICULAR

Karp (1937) studied radiographs of the feet of fifty children (twenty-five girls and twenty-five boys) taken every six months between the ages of nine months and four and a half years, and concluded that the average age of appearance of the ossific nucleus was between eighteen months and two years in girls and between two and a half and three years in boys. He also pointed out that not infrequently there were irregularities in ossification, the nucleus being sometimes flattened and occasionally fragmented or dense.

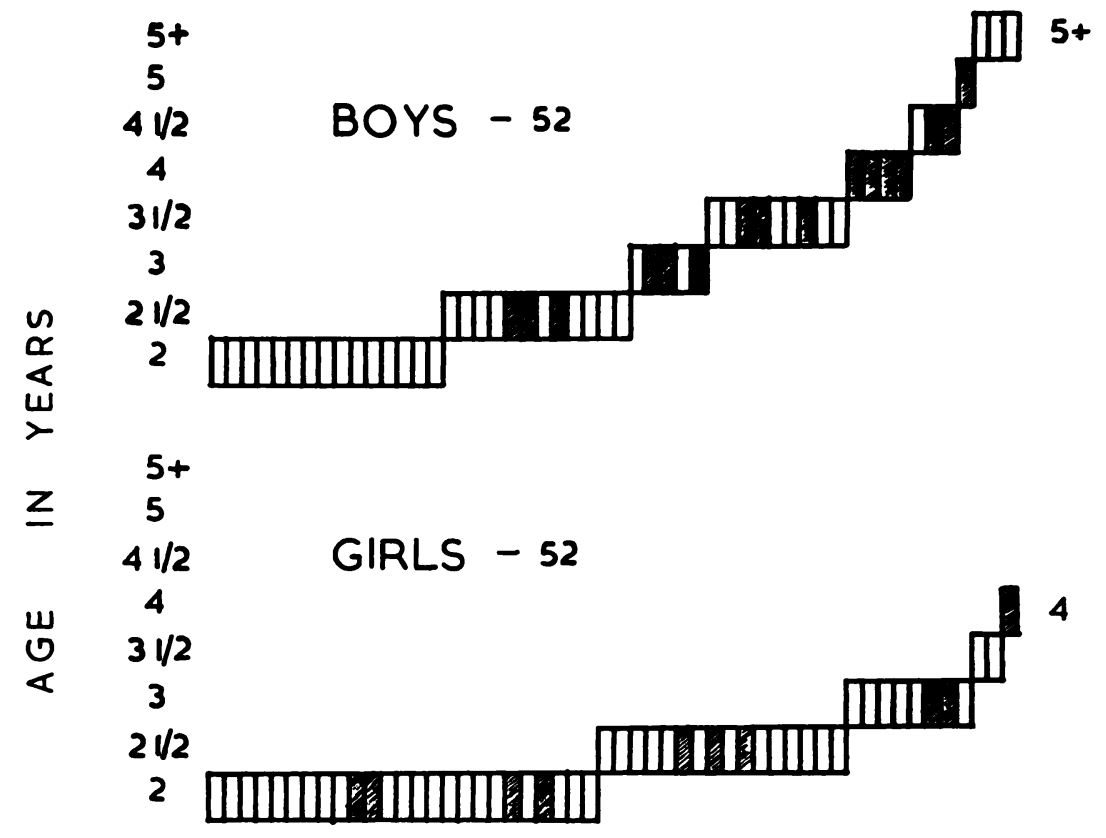

Fig. 2

Charts showing the differences in development of the navicular in twenty-six boys and twenty-six girls (fifty-two feet in each group). Each rectangle represents a single navicular and is shown at the age at which the nucleus first appears. Cross-hatching indicates a navicular whose ossification is abnormal. The three rectangles marked $5+$ in the boys' group indicate naviculars in which the nuclei had not appeared in the last films available at five years old.

In the present investigation serial radiographs of the feet of fifty-two normal children (twenty-six girls and twenty-six boys) were available, lateral films of both feet being taken at six-monthly intervals between the ages of two and five years inclusive. The height and weight of the child were also recorded. The sequence of ossification was observed by tracing the outline of both naviculars at $2,2 \frac{1}{2}, 3,3 \frac{1}{2}, 4,4 \frac{1}{2}$ and 5 years in each of the fifty-two children. Figure 1 shows four examples. In the first, a girl, the nucleus on both sides is well formed at two years and continues to develop normally. The second shows no abnormality of ossification but there is a definite difference in size between the two sides. In the third, the nucleus on the left side, which has lagged behind the right in development, becomes flattened and shows increased density about a year after its appearance. By five years the navicular, although still somewhat flattened, is regaining its normal structure. In the fourth example, both naviculars are delayed in appearance till three years on the left and three and a half years on the right, and they both show considerable irregularity in shape and odd patches of increased density. From a study of the full series it becomes clear that the pattern of development of the navicular is very variable. Abnormalities of ossification are common: they may consist of only minor irregularities in shape and size; or there may be gross changes that are apparently indistinguishable from those seen in Köhler's disease. 
Figure 2 is a diagram made to illustrate differences of development in boys and girls. Each rectangle represents a single navicular and is shown at the age at which its bony nucleus is first seen. Cross-hatching indicates a nucleus that shows abnormal ossification at the time of its first appearance or later. The series starts at an older age than Karp's, and in the feet that show a well formed nucleus in the first film at two years, it is not possible to say exactly at what age that particular nucleus appeared. Similarly, it is not possible to say how many of the retarded naviculars might develop changes between five and six years, the age at which Köhler's disease is common in boys. The three empty rectangles at the top of the boys' group indicate three feet in which the navicular had not appeared by five years, so that these might well show structural abnormalities at the time of their first appearance or later. Three conclusions, which are similar to Karp's, may be drawn from this survey: first, ossification occurs later in boys than girls; second, abnormalities are commoner in boys than in girls; and third, they are more frequent in naviculars that appear late.

\section{THE VASCULARISATION OF THE GROWING NAVICULAR}

It is often said that the navicular has a poor blood supply, but it is difficult to find precisely how and when this impression arose. Köhler (1928) wrote that " one roentgenologist determined on the grounds of anatomical research that the region of the scaphoid was poorly vascularised" but he omitted the name of the roentgenologist. It seems likely from other references that he was quoting the Italian Balli; unfortunately this author's papers are published in journals which are not available in any library in England. After a careful search, only two contributions have been found in which an attempt has been made to study the vascularisation of the bone (Velluda 1928, Zchakaja 1932); neither paper is adequately illustrated, but both

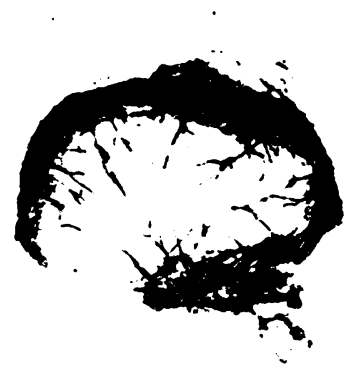

Fig. 3

Spalteholz photograph of an injected navicular from a boy aged eight weeks. $(\times 3$.

authors claimed that the bone was well supplied by radially penetrating vessels. In order to clarify this point, post-mortem injection studies were carried out on twenty-one naviculars at varying ages between birth and nineteen years.

It has not been possible to determine the source of the vessels entering the navicular bone by the method used in this investigation, but the following description was given by Velluda (1928). A branch from the dorsalis pedis artery crosses the dorsal surface of the navicular bone and gives off three to five branches. In most cases this vessel anastomoses with the medial plantar artery, forming an arcade around the tuberosity. Occasionally, the bone may 
receive small branches direct from the dorsalis pedis itself. The plantar surface is supplied by branches from the medial plantar artery.

After injection of Micropaque* by way of the external iliac artery (this is perfectly satisfactory in children) or the lower end of the femoral artery, the navicular is removed. It is decalcified, then cleared by the Spalteholz technique and studied under a dissecting microscope. All the illustrations in this paper are either fine-grain radiographs or Spalteholz photographs taken through the whole navicular from anterior to posterior. For the sake of clarity, each picture is orientated with the dorsal surface uppermost and the tuberosity on the right hand side (the negative being reversed if necessary).

Specimens at eight weeks (Fig. 3) and eight months (Fig. 4) show that the navicular is surrounded by a dense perichondrial network of vessels on the non-articular surfaces, and

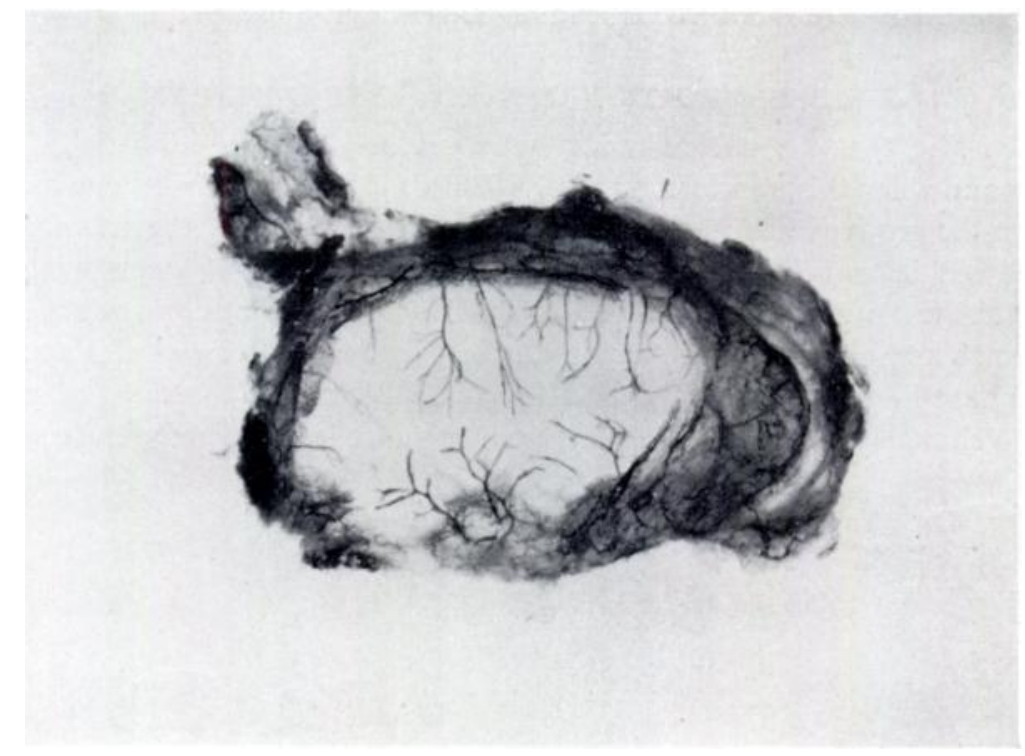

Fig. 4

Spalteholz photograph of an injected navicular from a girl aged eight months. $(\times 3$.

from this numerous arteries penetrate towards the centre of the cartilage. At twenty-one months (Fig. 5) the basic pattern is the same. The earliest appearance of an ossific nucleus is seen in Figure 6: bone has been laid down in relation to a single artery and vein. From this point three courses are theoretically possible. As the nucleus enlarges, it might be supplied by a single artery for a relatively short period, the other radial vessels becoming rapidly incorporated and forming a dense anastomotic network throughout the bone. Alternatively, separate centres of ossification might develop around several penetrating vessels. This probably can occur since clinical radiographs suggest that the bone does sometimes ossify from several centres, but it has not been found in any of the specimens in the present series. Finally, the nucleus might remain nourished by a single vessel until the age of five or six years, the radial vessels only entering the bone at a later date. Six naviculars between the ages of three and five years were available, and these suggest that the first pattern is the most usual. Figure 7 is a fine-grain radiograph of a navicular from a child three and a half years old. By studying the specimen in Spalteholz medium it can be seen that six arteries enter the bone and anastomose together.

* Berlin blue is not recommended for injection in children as it may produce widespread discoloration of the skin, including the face. 
Zchakaja (1932) examined four specimens between four and five years and found that on average eight to ten vessels penetrated the bony nucleus. His rather high figure, compared with that found in the present investigation, is probably explained by the fact that he studied only

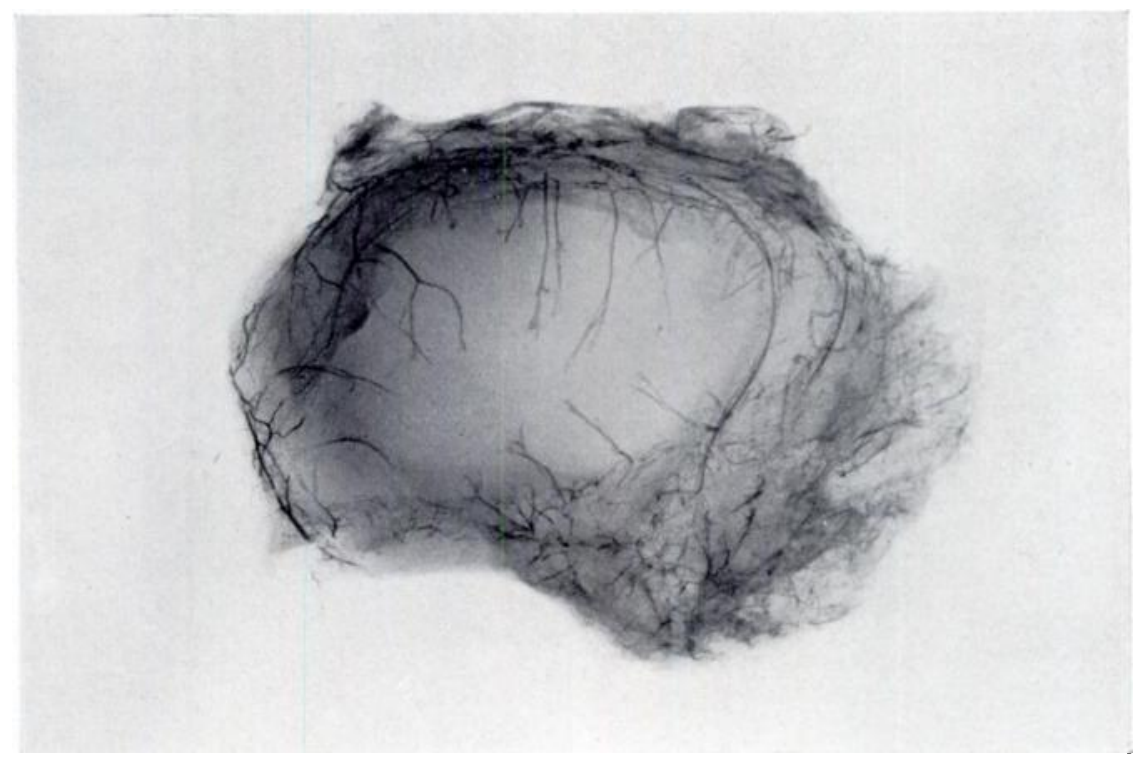

FIG. 5

Fine-grain radiograph of an injected navicular from a girl aged twenty-one months. $(\times 2$.)

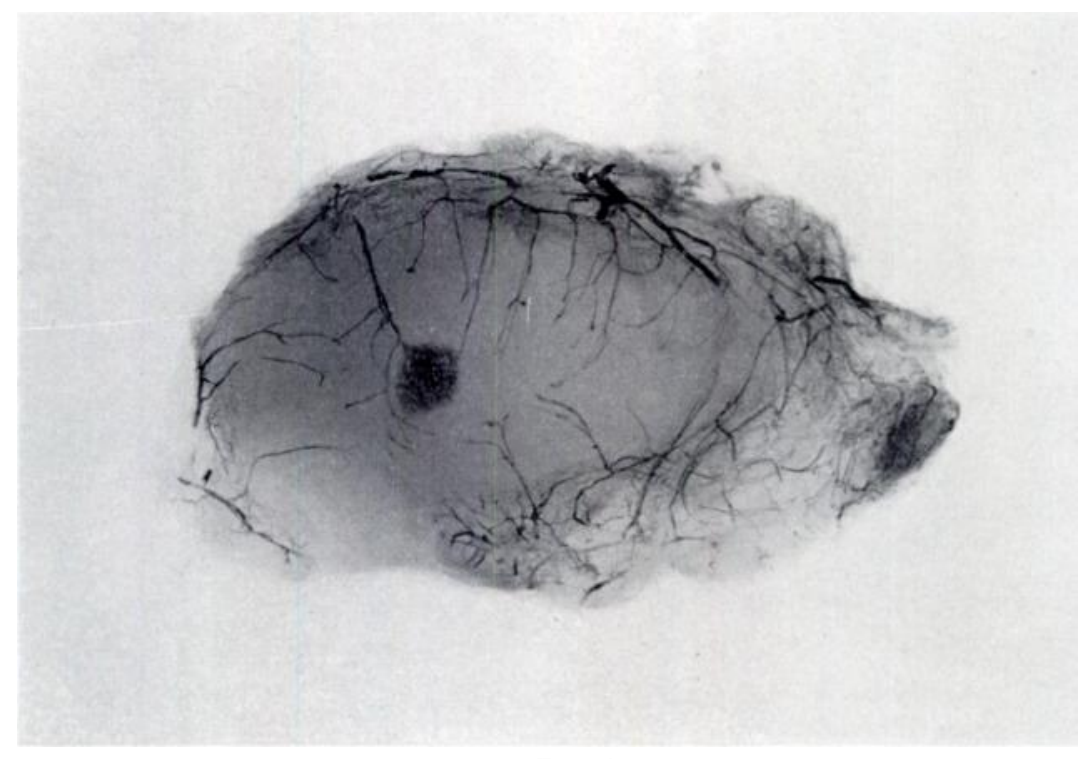

Fig. 6

Fine-grain radiograph of an injected navicular from a girl aged twenty-one months. $(\times 2$.) This is from the same child (opposite foot) as that illustrated in Figure 5. The first sign of ossification is seen: bone being laid down in relation to a single artery and vein. The vessel appearing to enter the nucleus to the right of its centre can be seen to be passing in front of it in the Spalteholz specimen.

radiographs. Vessels that appear to penetrate the bone may in fact be seen to pass in front of or behind it in the Spalteholz specimen. Zchakaja also gave figures for the other tarsal bones at the same age: cuboid, six to eight vessels; medial cuneiform, eight to ten vessels; intermediate

VOL. $40 \mathrm{~B}$, NO. 4, NOVEMBER 1958 


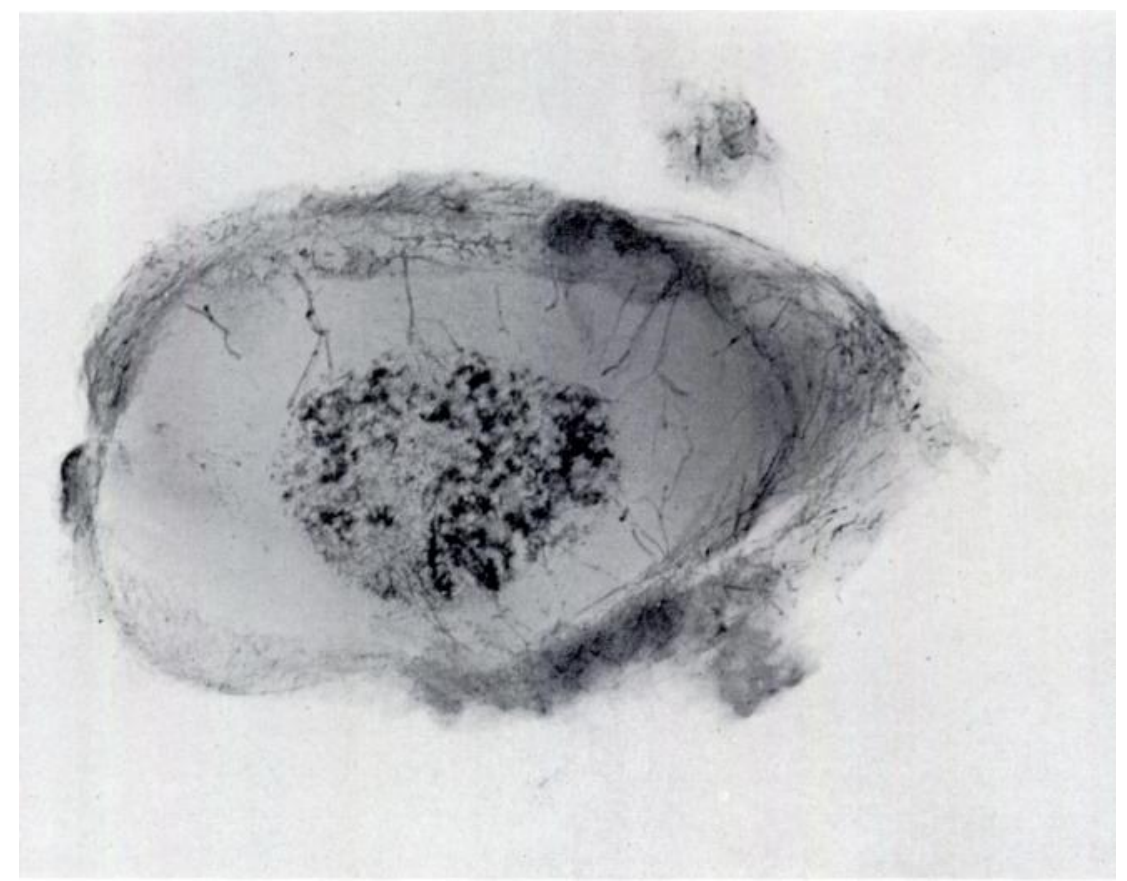

FiG. 7

Fine-grain radiograph of an injected and decalcified navicular from a girl aged three and a half years. ( $\times 2$.) From a study of the Spalteholz specimen six vessels are seen to enter the central bony nucleus which is outlined by an anastomotic network.

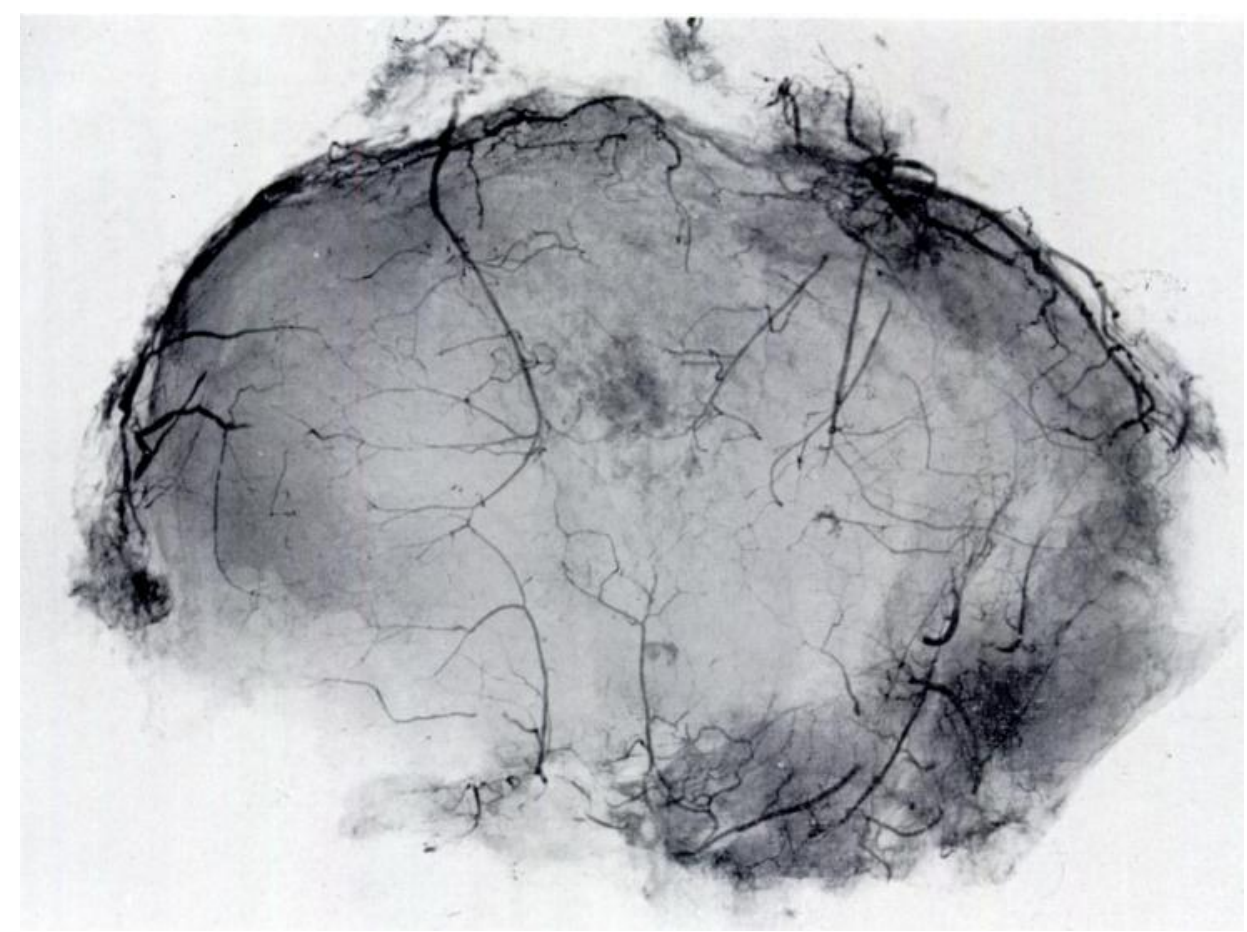

FIG. 8

Fine-grain radiograph of an injected and decalcified navicular from a girl aged seventeen years. $(\times 2$.) 


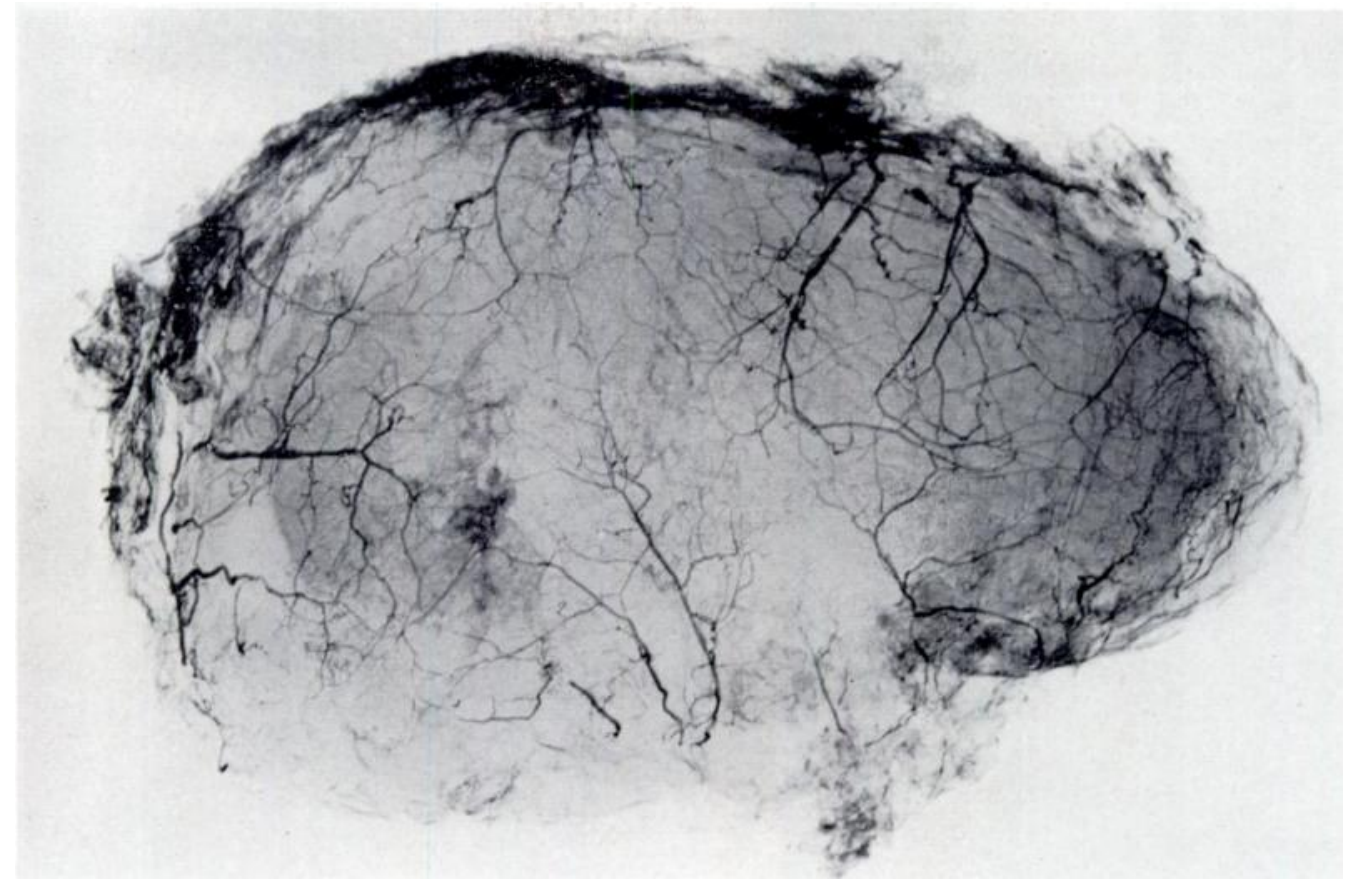

FIG. 9

Fine-grain radiograph of an injected and decalcified navicular from a youth aged nineteen years. $(\times 2$.)

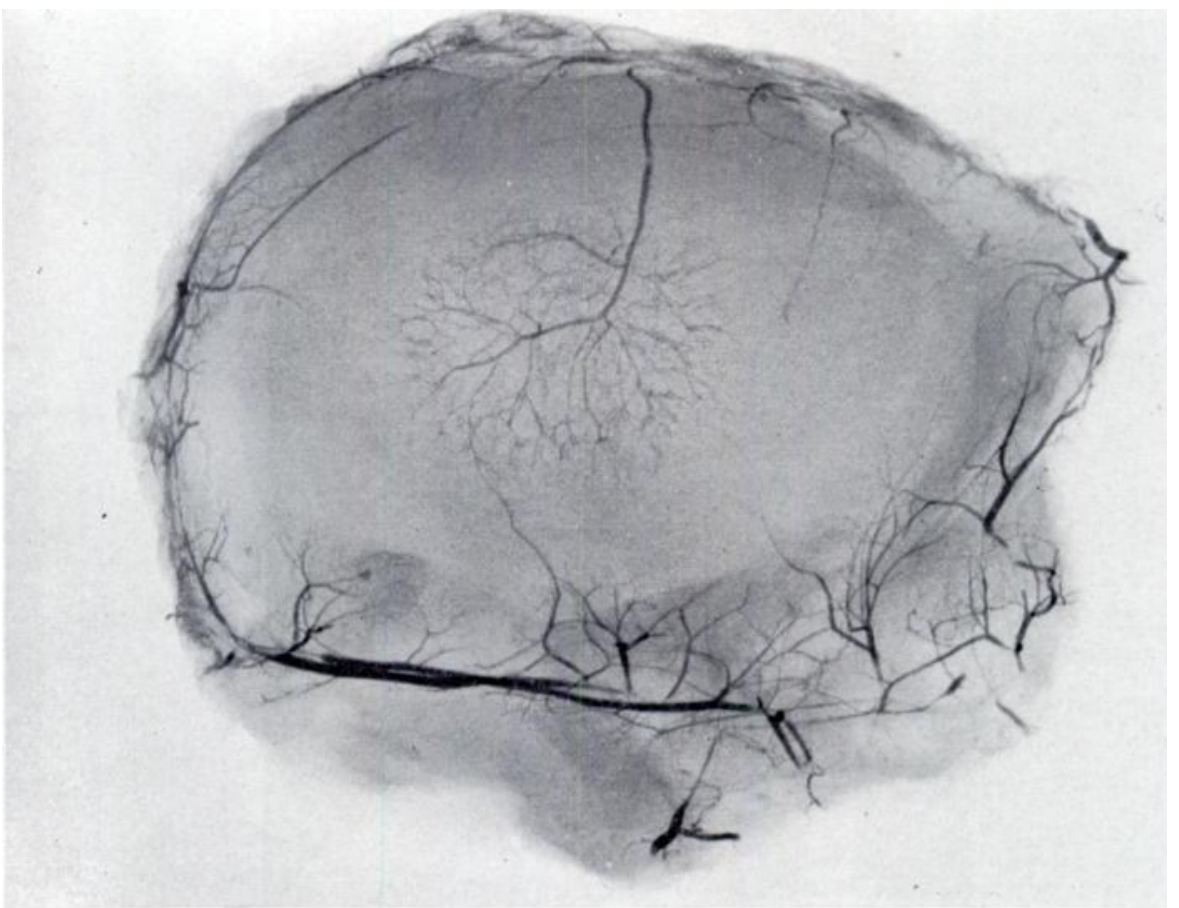

FIG. 10

Fine-grain radiograph of an injected and decalcified navicular from a girl aged four years. $(\times 2$.) A single main artery from the dorsal surface branches and outlines the whole of the central bony nucleus. A few smaller vessels also penetrate but take little part in the main anastomotic network.

VOL. 40 B, NO. 4, NOVEMBer 1958 
cuneiform, seven to eight vessels; lateral cuneiform, ten to eleven vessels. Although these figures may be high, as with the navicular, they suggest that there is normally little difference between the relative vascularisation of the tarsal bones.

The theory that there is a rapid incorporation of the chondral vessels into the expanding nucleus is further supported by the fact that the common adult pattern is almost identical with that of children (Figs. 8 and 9). Two further specimens suggest, however, that there may be important exceptions. Figure 10 shows the navicular of a child aged four in which a single dorsal artery branches and supplies almost the whole nucleus. A few small vessels also penetrate, but take little part in the main anastomotic network. The other anomalous specimen

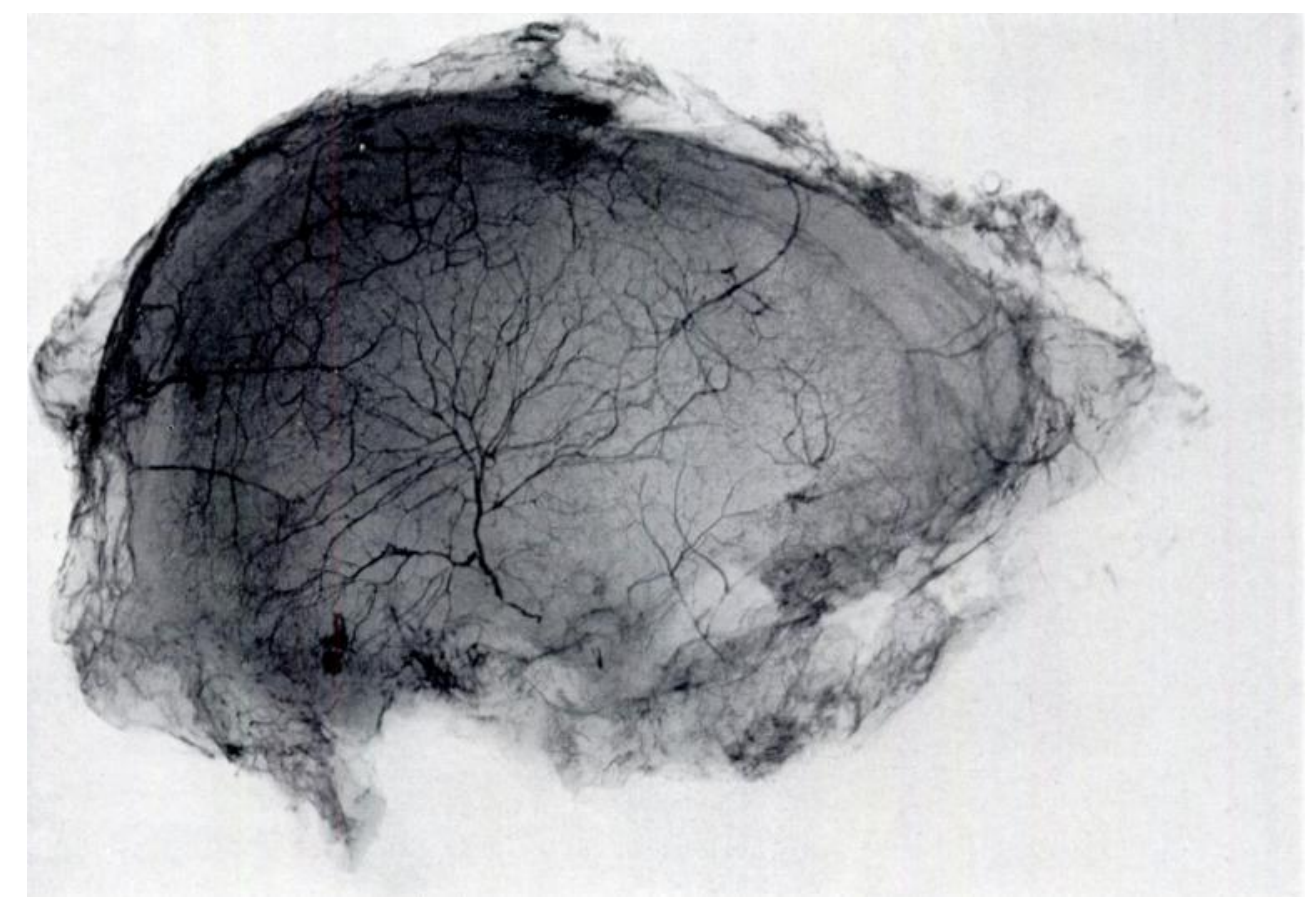

Fig. 11

Fine-grain radiograph of a decalcified navicular from a boy aged thirteen years. $(\times 2$.$) A large part of the$ bone, which now fills the whole specimen, is supplied by a single plantar artery. Other radial vessels have, however, been incorporated and play an important part in nourishing the bone.

(Fig. 11) suggests that a main plantar artery has been responsible for the supply of the whole nucleus up to a fairly late stage of development. Numerous, though short, radial vessels are, however, incorporated into the final bone.

It seems, therefore, that at five years (when Köhler's disease is most common) the ossific nucleus is supplied by five or six arteries which contribute fully to the vascular network within the bone. Alternatively, and less commonly, a single dorsal or plantar artery may be responsible for the nutrition of almost the whole nucleus.

\section{CLINICAL AND RADIOGRAPHIC FEATURES OF KÖHLER'S DISEASE}

These features are well known and are confirmed by a study of many series of cases which have been published, the most valuable recent contributions being by Recine (1954), Benedetti and Macconi (1954) and Martinie-Dubousquet (1956). The records of sixty-two patients with Köhler's disease who attended the Wingfield-Morris Orthopaedic Hospital and Nuffield Orthopaedic Centre between 1930 and 1957 have been studied. 
The condition is more common in boys than girls: in this series there were forty-nine boys and thirteen girls. The age incidence, indicating the time of onset of symptoms, is of significance: the average age of the forty-nine boys was five years and one month and of the thirteen girls three years and ten months. This is confirmed in other series (Karp 1937, Martinie-Dubousquet 1956). Boys are not only affected more frequently than girls but their symptoms begin at least a year later, and this fact must be explained in any theory of pathogenesis. The suggestion that boys injure themselves more easily is not convincing. In this group only two cases were recorded as affecting both feet, but it is possible that a higher incidence might be found if both feet were radiographed routinely. Martinie-Dubousquet (1956) noted eight bilateral cases out of twenty-four.

The child usually presents with pain and tenderness localised to the region of the navicular, and a limp. In a few cases there may have been an injury but more often than not the history

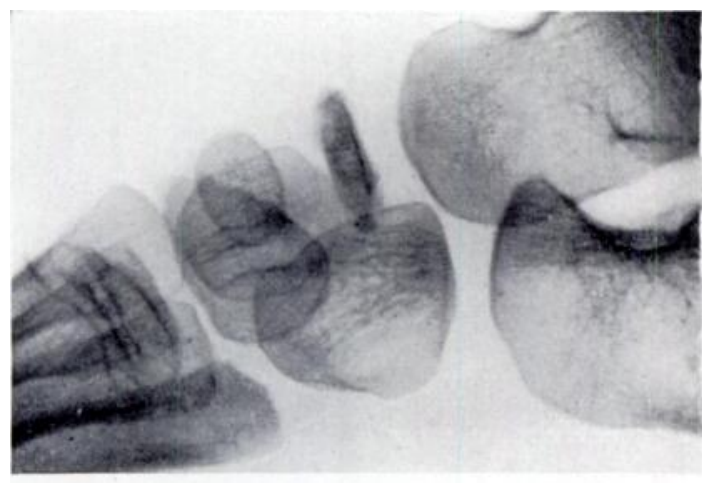

Fig. 12

Figure 12-Lateral radiograph of a boy aged four years who had pain and limp for the preceding five months. The navicular is flattened, with loss of normal trabecular pattern and areas of increased density. Figure 13Two years later. The bone is perhaps still slightly flattened but otherwise normal. Growth is not yet complete.

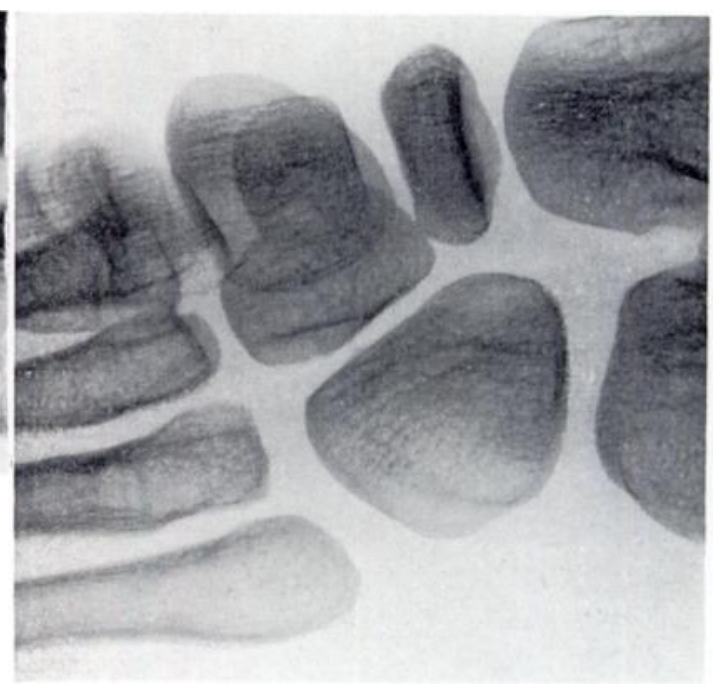

FIG. 13

is vague. Swelling is not uncommon and it was found in nearly half the children in this series. The reaction may be more severe: increased heat was noted in nine cases. The condition apparently is not more common in any particular shape of foot.

Radiographs show that the navicular is altered in shape, size and structure. Köhler (1928) emphasised the increased density and "want of structure" of the bone. Although there are many variations, a study of these cases suggests that there are two different types of radiological abnormality. In the first, which is the more common, the initial radiographs show the navicular to be flattened, as if it had been squashed, with patchy areas of increased density and loss of the normal trabecular pattern (Fig. 12). After two years the process has evolved, the bone being perhaps slightly flattened but otherwise normal (Fig. 13); growth is not yet complete. In the second type early films show the navicular to be of normal shape but uniformly increased in density compared with the other tarsal bones (Fig. 14). Four months later (Fig. 15) the dense bone is partly absorbed. After a further ten months (Fig. 16) all that remains is a faint narrow shadow. Twenty months from the onset (Fig. 17) the bone is beginning to re-form from several small centres of ossification.

A remarkable feature of Köhler's disease is the way in which the navicular is reconstituted to normal. This point is stressed and agreed on by most authors (Köhler 1928, Karp 1937, Benedetti and Macconi 1954, Martinie-Dubousquet 1956). The process may take 
six months, but more usually between eighteen months and three years. The only case in the literature in which the changes present in childhood have been shown to persist in any degree into adolescence was published by Brailsford (1939). Twelve patients have been seen ten or more years after the onset, and they all have normal naviculars. There are two patients in whom the last available radiographs show a minor residual deformity of the bone, but it has not been possible to follow these children into adult life. It is probable that most naviculars

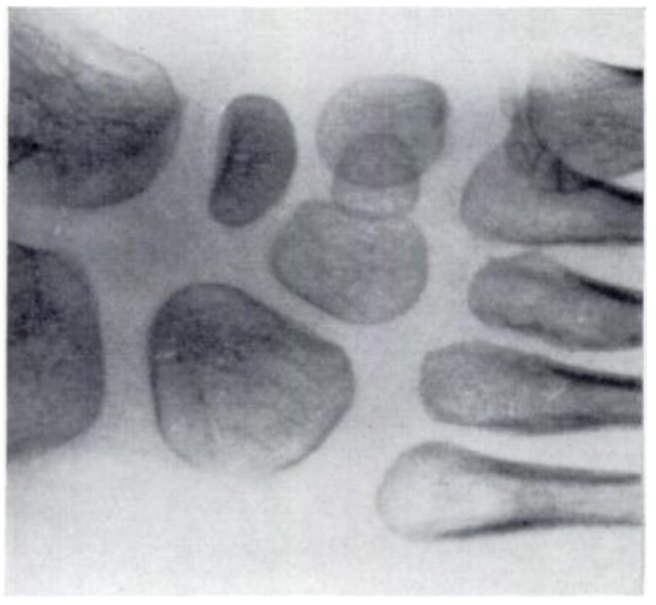

Fig. 14

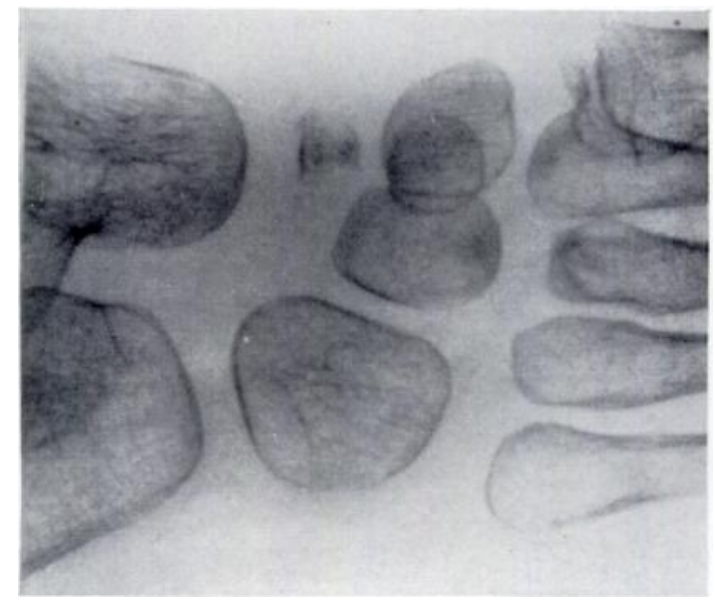

Fig. 15

Figure 14-Oblique radiograph of a boy aged five years, who had had symptoms for two months. The navicular is of normal size and shape but is of increased density compared with the other bones. Figure 15-Oblique radiograph four months later, showing partial absorption of the dense bone.

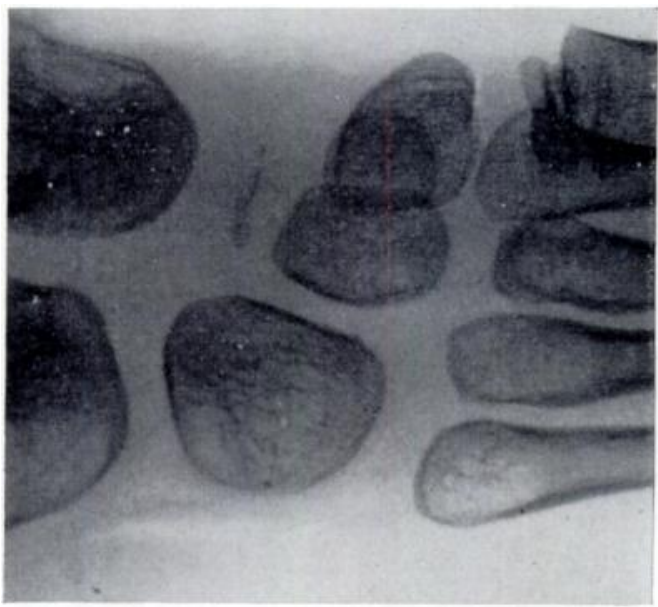

FIG. 16

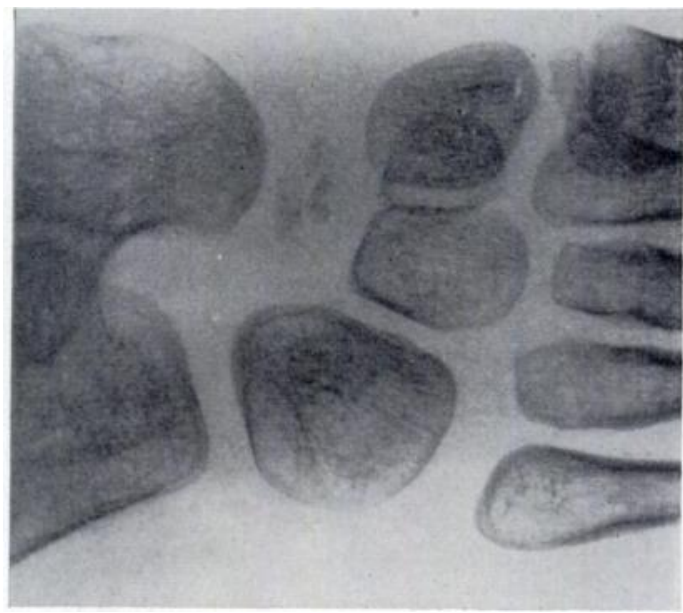

Fig. 17

Same case as Figures 14 and 15. Figure 16-Oblique radiograph ten months later. Only a faint narrow shadow indicates the remains of the navicular. Figure 17-Radiograph eleven months later, showing the beginning of re-formation of the bone from several small centres of ossification.

affected by Köhler's disease return to normal before growth of the foot is complete. There is no evidence to suggest that gross deformities that are seen in the adult bone are related to Köhler's disease (Waugh 1956).

Much of the evidence from which the nature of the lesion can be deduced is derived from radiographs. No opportunity has arisen during the present study to examine pathological specimens from children with the condition. Various authors (Kidner and Muro 1924, Lecène 
and Mouchet 1924; Speed 1927; Phemister, Brunschwig and Day 1930; Recine 1954) have described the microscopic appearances of the bone following biopsy or excision of the affected navicular. These usually show scattered areas of necrosis, bone destruction and absorption, but provide little helpful information about the etiology.

\section{DISCUSSION}

Many theories have been put forward to explain the nature and cause of Köhler's disease, but none provides a satisfactory answer. Phemister's (1930) evidence of an infective lesion has been discredited. Köhler (1928) himself was convinced that a single injury was not responsible, but he did suggest that the changes might be produced by an immoderate strain acting on a normal navicular for some months at a time, or a continuous normal strain acting on a navicular "weak in development"; he did not, however, pursue this argument further. Nagura and Kosuge (1939) were able to produce a somewhat similar lesion by damaging the cancellous bone of the rabbit's navicular with a sharp instrument, but experimental work of this nature has a limited practical application. The developmental theory is also unsatisfactory: the bone may be normal before the changes appear and thus preclude any primary epiphysial disorder. Fairbank (1957) had never seen changes like those of Köhler's disease in dysplasia epiphysialis multiplex.

Any concept of etiology must explain both abnormal ossification and Köhler's disease, and there is some evidence that both these disorders may have a mechanical basis. The position of the bone in the arch of the foot, and the fact that the navicular is always the last tarsal bone to ossify, suggest that the growing nucleus may be particularly susceptible to the compression forces of weight bearing. No relationship could be established between a child's weight or height and either the time of appearance of the ossific nucleus of the navicular or the development of irregularities in ossification. Similarly, Köhler's disease is no commoner in fat boys than in thin, nor in feet of any particular shape. Although it is disappointing not to be able to demonstrate any direct relationship between the changes and obvious mechanical imbalance, another explanation is possible.

It is reasonable to suppose that the surrounding cartilage can protect the bone from compression when the nucleus first appears. As growth continues, a point may be reached at which the proportion of cartilage to bone is reduced so that the bone begins to take stresses more or less directly. At this stage, which probably occurs between one and two years after the appearance of the ossific centre, the trabeculae become orientated horizontally (as can be seen in the lateral radiographs) to meet the demands of weight bearing.

If the nucleus develops relatively late, say at the age of four years, the critical point (which is probably of short duration) will be reached when the child is heavier and the weight bearing stress is greater than it would be if the nucleus appeared earlier, say at the age of two years. The retarded navicular is delayed in development absolutely in relation to the other tarsal bones and consequently is compressed by the already well ossified talus and cuneiforms. For these reasons a navicular whose nucleus appears late may be subjected to more pressure than its bone structure is able to withstand at a certain period during growth. Abnormalities of ossification may, therefore, be a response of the unprotected growing nucleus to normal stresses of weight bearing. The changes produced vary considerably from minor irregularities to flattening and increased density, and this will depend on the state of the nucleus, the mechanical factors and time over which they act. Increased density can be produced by crowding or increased thickness of trabeculae in response to pressure, or else result from ischaemia, as is likely in the fully developed lesion in Köhler's disease. Changes may be quite asymmetrical in each foot, as is seen in the serial radiographs of normal children. When this is the case, it is usual for the more affected navicular to be the one which appeared later and is the smaller of the two.

VOL. $40 \mathrm{~B}$, NO. 4, NOVEMBER 1958

$\mathbf{L}_{(8)}$ 
Although this theory might account for abnormal ossification, it does not explain how similar changes may be associated with symptoms. The answer may lie in the blood supply of the navicular. It may be suggested that if compression forces pass a certain point the nutrition of the nucleus is likely to be jeopardised. Vessels in the spongy bone may be occluded so that an ischaemic lesion develops. Soeur and de Racker (1952) put forward a similar concept to account for the vascular lesion in Perthes' disease. The production of ischaemia centrally in the ossific nucleus of the navicular seems more acceptable than the idea that it could be caused outside the bone. The navicular, unlike the femoral head at five to six years, has a profuse perichondrial network of vessels, and it is difficult to imagine a peripheral lesion that could cut off the blood supply to the central nucleus. The lesion produced by compression may either involve the vessels in the spongy bone or it may occur at the junction between the newly formed bone and the epiphysial cartilage. There is some evidence that the latter is more likely (Recine 1954).

The two radiographic types of Köhler's disease can be explained by variations in the vascular pattern of the affected bone. In the first, where the navicular is flattened and shows areas of increased density (Fig. 12), the ischaemia is patchy and may be related to a particular sector of the bone. This nucleus is probably penetrated by several vessels (as in Fig. 7) so that the lesion is incomplete. In the second type, which shows at first total increased density (Fig. 14) and is followed by disappearance of the nucleus (Figs. 15 and 16), the ischaemia is more or less complete, suggesting that the bone is largely supplied by a single vessel (as in Fig. 10). The presence of ischaemia in either case will be followed by reactive hyperaemia which will produce local pain, tenderness, swelling and sometimes increased heat. It is not possible to say how long either phase lasts, but this may be related to the vascular characteristics of the bone. There will be considerable variation in any given case; zones of ischaemia and hyperaemia may be present together in any particular navicular.

This theory explains some of the facts that are known about Köhler's disease. The nucleus of the navicular appears on average later in boys than girls, consequently abnormal ossification and Köhler's disease are far more common in boys than girls. This is to be expected when it is appreciated that the retarded navicular is exposed to greater compression than one which ossifies early. Furthermore, the boys in this series were, on average, 2 to $3 \mathrm{lb}$. heavier than the girls at any given time.

The next feature to be explained is the remarkable capacity that the navicular has for recovery. This is in direct contrast to the femoral head in Perthes' disease, where residual deformities are usual. Two factors may be responsible. First, radiographs show that although the bony nucleus is narrowed, the space between the talus and the cuneiforms is not decreased (this is true in abnormal ossification and in Köhler's disease), and this space is occupied by cartilage. This hypertrophied cartilage may be produced as a response to increased pressure or, more likely, to central bony ischaemia. It re-forms a thick layer of tissue, which can act as a shock absorber, and allows the bony nucleus to develop normally again. Second, and of greater importance, is the radial arrangement of the blood vessels. Even if a single artery supplies nearly the whole of the ossific centre, the perichondrial ring of vessels sends branches towards, if not into, the developing bone. This contrasts with the capital epiphysis of the femur, whose blood supply is limited to two main sources and where the open epiphysial plate is a barrier to revascularisation (Trueta 1957). No such barrier is present in the navicular, and penetration of the central nucleus by the radial vessels is easily possible, so allowing rapid revascularisation and reconstitution of the bone under the protection of the surrounding cartilage. In the less common type of Köhler's disease, the re-formation of the nucleus from a series of scattered points of new bone formation (Fig. 17) suggests that this process takes place initially at the endings of several vessels. 


\section{SUMMARY}

1. Serial radiographs of fifty-two normal children's feet, taken at six-monthly intervals between two and five years, have been reviewed.

2. Twenty-one naviculars have been injected post-mortem and the vascularisation of the growing bone investigated.

3. The records of sixty-two children with a diagnosis of Köhler's disease have been studied.

4. It is submitted that abnormal ossification results from compression of the bony nucleus at a critical phase during growth of a navicular bone whose appearance is delayed.

5. Symptoms in Köhler's disease are related to further compression which produces vascular changes in the bony nucleus. Consequent ischaemia is followed by hyperaemia which produces local pain, tenderness and swelling.

6. Two radiographic types of Köhler's disease are described and attributed to variations in the basic vascular pattern of the affected bone.

7. The usual complete recovery of the navicular is ascribed in part to the basic arrangement of numerous radially penetrating vessels.

My thanks are due to Professor J. Trueta, who has given me most valuable advice and constant encouragement throughout the time spent in this investigation. I am grateful to the surgeons of the Nuffield Orthopaedic Centre for permission to review their cases, and also to Dr F. H. Kemp and Dr Alice Stewart for allowing me access to the records of the Institute of Social Medicine, University of Oxford.

\section{REFERENCES}

Benedetti, G. B., and Macconi, L. (1954): La sindrome scafoidea di Köhler e le sue influenze sulla statica del piede. Atti del XXXIX Congresso della Società Italiana di Ortopedia e Traumatologia, Napoli 13-14-15 ottobre 1954, p. 117.

Brailsford, J. F. (1939): Osteochondritis of the Adult Tarsal Navicular. Journal of Bone and Joint Surgery, 21, 111.

Fairbank, Sir T. (1957): Personal communication.

KARP, M. G. (1937): Köhler's Disease of the Tarsal Scaphoid. Journal of Bone and Joint Surgery, 19, 84.

Kidner, F. C., and Muro, F. (1924): Köhler's Disease of the Tarsal Scaphoid or Os Naviculare Pedis Retardatum. Journal of the American Medical Association, 83, 1,650.

KöHLER, A. (1908): Ueber eine häufige bisher anscheinend unbekannte Erkrankung einzelner kindlicher Knochen. Muenchener medizinische Wochenschrift, 55, 1,923.

KöHLER, A. (1928): Röntgenology, p. 114. London: Baillière, Tindall and Cox.

Lecène, P., and Mouchet, A. (1924): La scaphoidite tarsienne. Revue d’Orthopédie, 3, série 11, 105. MARTINIE-Dubousquet, J. (1956): Scaphoidite tarsienne (première maladie de Köhler). Semaine des Hôpitaux de Paris-Annales de Chirurgie, 32, 177.

Nagura, S., and Kosuge, S. (1939): Die Enstehung und das Wesen der Köhler'schen Krankheit des Navikulare. Zentralblatt für Chirurgie, 66, 1,186.

Phemister, D. B., Brunschwig, A., and Day, L. (1930): Streptococcal Infections of the Epiphyses and Short Bones. Journal of the American Medical Association, 95, 995.

ReCINe, A. (1954): Le Osteochondriti. Relazione al XXXIX Congresso della Società Italiana di Ortopedia e Traumatologia, Napoli, 13-15 ottobre 1954.

SOEUR, R., and RACKER, C. de (1952): Pathogénie et classement des ostéochondrites en général. Première Partie. L'aspect anatomopathologique de l'ostéochondrite et les théories pathogéniques qui s'y rapportent. Acta Orthopaedica Belgica, 18, 57.

SPEED, K. (1927): Köhler's Disease of the Tarsal Scaphoid Bone. Transactions of the American Surgical Association, 45, 179.

TruetA, J. (1957): The Normal Vascular Anatomy of the Human Femoral Head during Growth. Journal of Bone and Joint Surgery, 39-B, 358.

Trueta, J., and Harrison, M. H. M. (1953): The Normal Vascular Anatomy of the Femoral Head in Adult Man. Journal of Bone and Joint Surgery, 35-B, 442.

Velluda, C. (1928): Sur la vascularisation du scaphoide du tarse. Annales d'Anatomie Pathologique, 5, 1,016. WAUGH, W. (1956): Structural Deformities of the Outer Third of the Adult Tarsal Navicular. Proceedings of the Royal Society of Medicine (Section of Orthopaedics), 49, 965.

ZchaKaJA, M. J. (1932): Blutversorgung der Knochen des Fusses (Ossa pedis). Fortschritte auf dem Gebiete der Röntgenstrahlen, 45, 160.

VOL. $40 \mathrm{~B}$, NO. 4, NOVEMBER 1958 